\title{
Simultaneous impacts of Joule heating and variable heat source/sink on MHD 3D flow of Carreau-nanoliquids with temperature dependent viscosity
}

https://doi.org/10.1515/nleng-2017-0132

Received October 7, 2017; revised February 25, 2018; accepted April 7, 2018.

\begin{abstract}
The 3D flow of non-Newtonian nanoliquid flows past a bidirectional stretching sheet with heat transfer is investigated in the present study. It is assumed that viscosity of the liquid varies with temperature. Carreau nonNewtonain model, Tiwari and Das nanofluid model are used to formulate the problem. The impacts of Joule heating, nonlinear radiation and non-uniform (space and temperature dependent) heat source/sink are accounted. Al$\mathrm{Cu}-\mathrm{CH}_{3} \mathrm{OH}$ and $\mathrm{Cu}-\mathrm{CH}_{3} \mathrm{OH}$ are considered as nanoliquids for the present study. The solution of the problem is attained by the application of shooting and R.K. numerical procedures. Graphical and tabular illustrations are incorporated with a view of understanding the influence of various physical parameters on the flow field. We eyed that using of $\mathrm{Al}-\mathrm{Cu}$ alloy nanoparticles in the carrier liquid leads to superior heat transfer ability instead of using only Aluminum nanoparticles. Weissenberg number and viscosity parameter have inclination to exalt the thermal field.
\end{abstract}

Keywords: Carreau fluid, Joule heating, Varying viscosity, Irregular heat sink/source, Alloy nanoparticles

\section{Introduction}

Basically the fluids that are utilized in many industrial processes possess inferior heat transport capacity. Methanol, kerosene, water and Ethylene glycol come under this cate-

\footnotetext{
J. V. Ramana Reddy, Department of Science and Humanities, Krishna Chaitanya Institute of Technology and Sciences, Markapur, India

*Corresponding Author: V. Sugunamma, Department of Mathematics, S. V. University, India, E-mail: vsugunar@gmail.com *Corresponding Author: N. Sandeep, Fluid Dynamics Division, VITVellore, India, E-mail: nsreddy.dr@gmail.com
}

gory. Multiple researchers have been worked severely with the aim of magnifying the heat transport power of fluids and undoubtedly they succeeded. Due to their research, the occurrence of new technology in nano/ferrofluids was happened.

Before 1995 there is no word of nanofluid, even though there are some methods to develop the thermal efficiency of regular fluids by using Maxwell's idea. For the first time, Choi [1] instigated the heat transport efficiency of routine fluids (water, oils etc.) can be enhanced by intermingling the tiny (1-100 nm size) solid particles of $\mathrm{Fe}, \mathrm{Au}, \mathrm{TiO}_{2}$ and $\mathrm{SiO}$ etc. He termed that new attained fluid as nanofluid. Following the Choi's criterion, plenty of research work is produced in this discipline. The analysts of fluid dynamics are also constructing the flow models with respect to nanofluids. The research of magneto hydrodynamic fluid flows comprising of nanoparticles have fantastic benefits due to medical, engineering, industrial implementations such as surgeries, cancer therapy, drug delivery and production of coolant oils etc. Also nanofluids are extensively used in solar collectors, radiators and in nuclear reactors. Eastman et al. [2] presented prodigious work on nanoliquids employing EG as the carrier liquid and $\mathrm{Cu}$ nanoparticles. They observed the efficiency of thermal conductivity of both EG and EG-Cu fluids and finalized that blending of solid Cu-nanoparticles causes an enhancement in the thermal efficiency of regular fluids (EG). Buongiorno [3] constructed a strange flow model of nanofluids to understand the Brownian motion of nanoparticles.

Mabood et al. [4] considered the motion of nanoliquid via circular cylinder using $\mathrm{Cu}$ and $\mathrm{Al}_{2} \mathrm{O}_{3}$ nanoparticles and deduced that fluid with $\mathrm{Cu}$ particles exhibits good thermal performance when compared to the fluid with $\mathrm{Al}_{2} \mathrm{O}_{3}$ particles. Reddy et al. [5] reported the time dependent Brownian moment of nanoliquids across a variable thickness geometry accounting slip velocity. In some situations, using the combination of more than one type of solid particles possesses excessive heat transfer ability than using them individually. So, Noor et al. [6] presented a theoretical work 
on the attributes of Cu-Al alloy nanoparticles. Raju et al. [7] used alloy nanoparticles to investigate the nanofluid flow due to cone employing Carreau model. They stated that TiAl-V alloy exhibits poor thermal performance than Ni-CrFe alloy.

The analysis of non-Newtonian flows is a widespread topic of modern research. Non-Newtonian fluids cover many products which we come across regularly such as mud, juices, lubricant oils and cosmetics. It is salient to understand the thermal transfer attributes of these fluids on account of their merits in bio, nuclear, polymer and material processes. Multiple models are accessible from the previous work for better grasping of non-Newtonian flows. Among them a strange model due to Carreau is adopting by regular researchers owing to its striking characteristics. Boyd et al. [8] utilized the Lattice-Boltzmann procedure for the analysis of oscillatory blood flows employing two distinct non-Newtonian models. The magnetohydrodynamic stagnation point flows induced by a shrinking surface using Carreau model was addressed by Akbar et al. [9]. On the other hand, the 3D moment of a fluid via linear surface was illustrated by Malik et al. [10] by using the Williamson non-Newtonian model. This investigation states that higher values of Williamson parameter improve the shear stress. The heat transport mechanism in the time dependent Carreau fluid consisting of nanoparticles was explained by Khan and Azam [11]. Similar research was carried out by Hayat et al. [12] to analyse the flows of tangent hyperbolic fluids over a slender surface. Very recently, Khan et al. [13] established a mathematical relation for time dependent 3D flow of Carreau fluid over a stretching surface.

Adegbie and Alao [14] elaborated the Couette flows with temperature dependent viscosity. Attia [15] did an extension of this research to examine the unsteady Couette flows considering dust particles in the fluid. A bundle of investigations has been given on temperature dependent viscous flows using distinct models [16-18], owing to their novelty in heat transport mechanism. Nadeem et al. [19] handled the 3D flow of non-Newtonian liquid along a penetrable surface. They obtained the problem solution by Runge-Kutta based shooting technique. Considering the flow domain as nonlinear and stretchable, Khan et al. [20] under taken the similar work. Rashidi et al. [21] stated an advanced mathematical model to investigate the impact of $2^{\text {nd }}$ order slip velocity on the motion of nanoliquid past a contracting surface. The radiative micropolar fluid flow past a convective surface with the existence of slip velocity was elucidated by Ramzan et al. [22]. The results of Lorentz force application (in aligned angle) on ferroliquid flows driven by a variable thickness sheet were declared by Reddy et al. [23]. Distinct studies [24-27] were presented by the researchers to peruse the action of varying heat sink/source (depending upon space and temperature) on convective flows. They employed the flow geometries like wedge, cone, stretched surface and cylinder etc.

Shah et al. [28] considered the dissipative 2D flow of Carreau fluid over a stretched geometry with varying thermal conductivity. This paper concludes that dissipation in the flow causes heat generation. The dissipative chemically reacting flow induced by a convective slender sheet was discussed by Babu et al. [29]. Series solutions are presented by Muhammad et al. [30] to discuss the squeezed motion of a liquid between two surfaces. Shehzad et al. [31] worked on discovering the impact of Brownian motion on 3D nonlinear radiative flows. Raju and Sandeep [32] modeled the flows of two different non-Newtonian types with time dependence. Shehzad et al. [33] dissected the motion of Jeffrey fluid with heat source and watched that Nusselt number is high in 3D flow compared to 2D flow. The problem of heat transport in Williamson flow model over a multi directional non linear geometry was researched by Bilal et al. [34]. They accounted temperature dependent viscosity (TDV) while giving the mathematical model. Reddy et al. [35] performed a phenomenal comparative discussion on nonlinearly radiative ferroliquids with two dissimilar base liquids considering TDV. They concluded that kerosene works better than methanol in cooling processes. Hina et al. [36] examined the flow of Oldroyd-B fluid over a bidirectional stretching geometry with nonFourier heat flux approach. The influence of variable viscosity on the boundary layer flow of nanofluids was examined by Shekar et al. [37].

Joule heat/Ohmic heat occurs as electric current due to the interaction between fluid particles. The concept of this resistive heating is applicable in nuclear engineering and in making of multiple electrical products like fan heaters, soldering iron and cartridge heaters. Kaladhar et al. [38] and Praveen and Alim [39] studied the influence of Joule heating on magnetohydrodynamic flows. Similarly, the studies $[40,41]$ are made to scrutinize the flow characteristics of third grade and Jeffrey fluids respectively under the impact of Joule heating. Dogonchi and and Ganji [42] introduced a model to probe the impact of Joule heat on nanoliquid flow between unparallel surfaces.

In view of the analysis of above articles and many other, we may confirm that no endeavour was made by anyone to look into the motion of temperature dependent viscous 3D flows (with nanoparticles) with the action of Joule's heat and varying heat sink/source. Ergo, we designed an advanced mathematical model exploiting Carreau-nanofluid model filling the above stated gap. For 
this we continued the work of Reddy et al. [37]. Results are imparted to comprehend the impression of emerging physical quantities on the flow field and debated accordingly.

\section{Formulation of the Problem}

Let us consider the three dimensional incompressible flow of Carreau-nanofluid past a bidirectional stretching surface with temperature dependent viscosity. $x y$-plane is deemed to be sheet and $z$-axis is making an angle of $90^{\circ}$ with sheet. Magnetic field is implemented in the direction of $z$-axis. Fig. 1 expounds the flow situation. $u_{s}(x)=d_{1} x$ and $v_{s}(x)=d_{2} y$ are presumed to be the stretching velocities of the surface in $x, y$ - directions respectively. $T_{\infty}, T_{S}$ symbolize the temperatures distant from the sheet and nearby it respectively.

The below stated presumptions are incorporated to frame the basic flow equations.

- The flow is not unsteady but laminar.

- Joule heating and variable heat sink/source are assessed.

- $\quad \mathrm{Cu}, \mathrm{Al}-\mathrm{Cu}$ alloy nanoparticles are employed for nanofluid with methanol as the carrier liquid.

- Induced magnetic field and chemical reaction are not reckoned.

- The prominent Tiwari and Das model of nanofluid is utilized.

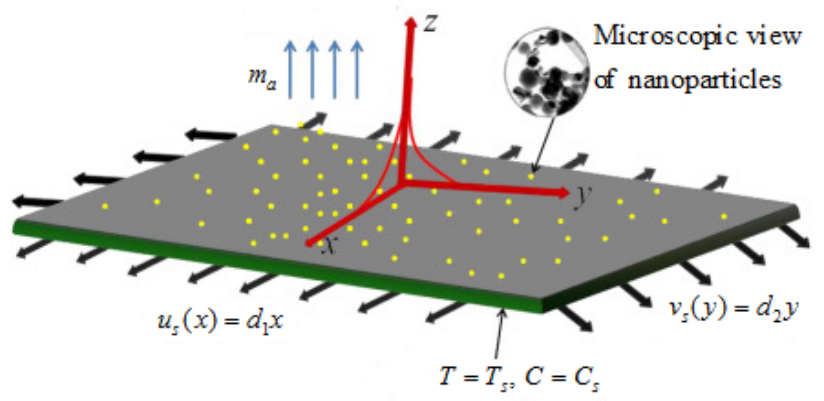

Fig. 1: Flow Geometry

After the careful implementation of above enunciated hypothesis the momentum and energy equations of 3D motion of Carreau-nanofluid are, (see [7, 27, 37, 41])

$$
\frac{\partial u}{\partial x}+\frac{\partial v}{\partial y}+\frac{\partial w}{\partial z}=0
$$

$$
\begin{aligned}
& \left(u \frac{\partial u}{\partial x}++v \frac{\partial u}{\partial y}+w \frac{\partial u}{\partial z}\right)=\frac{1}{\rho_{N f}}\left(\frac{\partial}{\partial z}\left(\mu_{N f}(T) \frac{\partial u}{\partial z}\right)\right. \\
& \left.+\lambda^{2}(1.5)(m-1)\left(\frac{\partial u}{\partial z}\right)^{2} \frac{\partial}{\partial z}\left(\mu_{N f}(T) \frac{\partial u}{\partial z}\right)-m_{a}^{2} \sigma_{N f} u\right),
\end{aligned}
$$

$$
\begin{gathered}
\left(u \frac{\partial v}{\partial x}++v \frac{\partial v}{\partial y}+w \frac{\partial v}{\partial z}\right)=\frac{1}{\rho_{N f}}\left(\frac{\partial}{\partial z}\left(\mu_{N f}(T) \frac{\partial v}{\partial z}\right)\right. \\
\left.+\lambda^{2}(1.5)(m-1)\left(\frac{\partial v}{\partial z}\right)^{2} \frac{\partial}{\partial z}\left(\mu_{N f}(T) \frac{\partial v}{\partial z}\right)-m_{a}^{2} \sigma_{N f} v\right) \\
\quad\left(\rho C_{p}\right)_{N f}\left(u \frac{\partial T}{\partial x}+v \frac{\partial T}{\partial y}+w \frac{\partial T}{\partial z}\right)=k_{N f} \frac{\partial^{2} T}{\partial z^{2}}+Q^{\prime \prime \prime} \\
+\sigma_{N f} m_{a}^{2} u^{2}+\frac{16 \sigma_{e}}{3 k_{e}} \frac{\partial}{\partial z}\left(T^{3} \frac{\partial T}{\partial z}\right)
\end{gathered}
$$

In view of the flow geometry, we use the following boundary conditions

$$
\begin{aligned}
& u=d_{1} x, v=d_{2} y, w=0, T=T_{s} \text { at } z=0, \\
& u \rightarrow 0, v \rightarrow 0, T \rightarrow T_{\infty}, \text { as } z \rightarrow \infty,
\end{aligned}
$$

In the momentum equations, $u, v$ and $w$ stands for flow velocities in the directions of $x, y$ and $z$ axes correspondingly, nanoliquid's density is $\rho_{N f}=$ $\rho_{B f}\left((1-\Phi)+\Phi\left(\frac{\rho_{N p}}{\rho_{B f}}\right)\right)$, nanoliquid's temperature dependent dynamic viscosity is $\mu_{N f}(T)=\mu_{B f}(1-\Phi)^{-5 / 2} e^{-\beta \theta}$, magnetic field strength is $m_{a}$, power law index is $m$, constant of time is $\lambda$, nanoliquid's electrical conductivity is $\sigma_{N f}=\sigma_{B f}\left(1-\frac{3(1-\sigma) \Phi}{(2+\sigma)+\Phi(1-\sigma)}\right)$ with $\sigma=\frac{\sigma_{N p}}{\sigma_{B f}}$.

In the energy equation, fluid temperature is $T$, nanoliquids's heat capacity is $\left(\rho C_{p}\right)_{N f}=$ $\left(\rho C_{p}\right)_{B f}\left((1-\Phi)+\frac{\left(\rho C_{p}\right)_{N p}}{\left(\rho C_{p}\right)_{B f}} \Phi\right)$. Further, $k_{e}, \sigma_{e}$ correspondingly stands for mean absorption and Stefan-Boltzmann coefficients, thermal conductivity of nanoliquid is $k_{N f}=k_{B f}\left[\frac{\left(k_{N p}+2 k_{B f}\right)-2 \Phi\left(k_{B f}-k_{N p}\right)}{\left(k_{N p}+2 k_{B f}\right)+\Phi\left(k_{B f}-k_{N p}\right)}\right]$.

The term denoting the existence of non-uniform heat absorption and generation is (See Kumar et al. [24])

$$
Q^{\prime \prime \prime}=\frac{k_{B f} d_{1}}{v_{B f}}\left(f^{\prime} H_{1}\left(T_{S}-T_{\infty}\right)+\left(T-T_{\infty}\right) H_{2}\right)
$$

Here, $\Phi$ is the percentage of nanoparticles blending with water (base liquid), the suffixes $N p, B f, N f$ signify the thermal attributes of nanoparticles, base fluid and nanofluid respectively. $\beta$ is the viscosity parameter, $\theta$ is the dimensionless fluid temperature, $H_{1}, H_{2}, d_{1}, d_{2}$ are constants. $H_{1}, H_{2}<0$ denote internal heat sink, $H_{1}, H_{2}>0$ denote internal heat source. 


\section{Solution of the problem}

After neglecting the terms of $2^{\text {nd }}$ and higher order from the expansion of $e^{-\beta \theta}$, We arrive at

$$
e^{0 \beta \theta}=1-\beta \theta+O\left(\beta^{2}\right) .
$$

The beneath said similarity transfigurations (satisfying continuity Eqn. (1)) will fit for the current problem.

$$
\begin{aligned}
& u=d_{1} x f^{\prime}(\xi), v=d_{2} y g^{\prime}(\xi), w=-\sqrt{v_{B f} / d_{1}}\left(d_{1} f+d_{2} g\right), \\
& \theta=\left(T-T_{\infty}\right) /\left(T_{s}-T_{\infty}\right), \xi=\sqrt{d_{1} / v_{B f}} z,
\end{aligned}
$$

In the above Eqn. $\xi$ is the similarity variable, $f^{\prime}, g^{\prime}$ are non-dimensional fluid velocities in $x, y$-directions and $v_{b f}$ is the kinematic viscosity of base fluid.

Substitution of Eqs. (6)-(8) along with the nanofluid expressions $\rho_{N f}, k_{n f}, \mu_{N f},\left(\rho C_{p}\right)_{N f}, \sigma_{N f}$ in Eqs. (2)-(4) leads to the following system of nonlinear ODE.

$$
\begin{aligned}
& (1-\Phi)^{-5 / 2}(1-\beta \theta) f^{\prime \prime \prime}+\left(E_{1}(f+\Lambda g)-(1-\Phi)^{-5 / 2} \beta \theta^{\prime}\right) f^{\prime \prime} \\
& =E_{1} f^{\prime 2}+M f E_{4} f^{\prime}+(1-m) 1.5 W b\left(f^{\prime \prime}\right)^{2}(1-\Phi)^{-5 / 2} \\
& \left((1-\beta \theta) f^{\prime \prime \prime}-\beta f^{\prime \prime} \theta^{\prime}\right)
\end{aligned}
$$

$(1-\Phi)^{-5 / 2}(1-\beta \theta) g^{\prime \prime \prime}+\left(E_{1}(f+\Lambda g)-(1-\Phi)^{-5 / 2} \beta \theta^{\prime}\right) g^{\prime \prime}$

$=E_{1} g^{\prime 2} \Lambda+M f E_{4} g^{\prime}+(1-m) 1.5 W b\left(g^{\prime \prime}\right)^{2}(1-\Phi)^{-5 / 2}$

$\left((1-\beta \theta) g^{\prime \prime \prime}-\beta g^{\prime \prime} \theta^{\prime}\right)$

$$
\begin{aligned}
& \left(\operatorname{Rd}\left(\left(\theta_{r}-1\right) \theta+1\right)^{3}+E_{2}\right) \theta^{\prime \prime} \\
& =\left(\left(\theta_{r}-1\right) \theta+1\right)^{2} R d 3\left(1-\theta_{r}\right) \theta^{\prime 2}-M f E k E_{4} f^{\prime 2}-H_{1} f^{\prime} \\
& -H_{2} \theta-\operatorname{Pr} E_{3}(f+\Lambda g) \theta^{\prime},
\end{aligned}
$$

The new boundary restrictions in view of Eqn. (8) are,

$$
\begin{aligned}
& f(0)=0, f^{\prime}(0)=1, f^{\prime}(\infty)=0, \\
& g(0)=0, g^{\prime}(0)=\Lambda, g^{\prime}(\infty)=0, \\
& \theta(0)=1, \theta(\infty)=0,
\end{aligned}
$$

In Eqs. (9)-(11), $E_{1}=\rho_{B f}^{-1} \rho_{N f}, E_{2}=k_{B f}^{-1} k_{N f}$, $E_{3}=\left(\rho C_{p}\right)_{B f}^{-1}\left(\rho C_{p}\right)_{N f} E_{4}=\sigma_{B f}^{-1} \sigma_{N f}$. Also we have some dimensionless physical parameters such as $\operatorname{Pr}, M f, \Lambda, \theta_{r}, E k, W b$ and $R d$ given below.

$\operatorname{Pr}=\mu_{B f} k_{B f}^{-1}\left(C_{p}\right)_{B f}$, is the Prandtl number,

$M f=\frac{m_{a}^{2} \sigma_{B f}}{d_{1} \rho_{B f}}$, is the parameter of magnetic field,

$\Lambda=d_{2} / d_{1}$, is the parameter of stretching ratio,

$\theta_{r}=T_{s} / T_{\infty}$, is the ratio of surface temperature to the ambient temperature,

$E k=\frac{u_{s}^{2}}{\left(C_{p}\right)_{B f}\left(T_{s}-T_{\infty}\right)}$, is the Eckert number,
$W b$, is the Weissenberg number,

$R d=\frac{16 T_{\infty}^{3} \sigma_{e}}{3 k_{b} k_{e}}$, is the radiation parameter.

Friction factors in $x, y$ - axis directions $\left(C_{f_{x}}, C_{f_{y}}\right)$ along with Nusselt number $\left(N u_{x}\right)$ are also extracted to focus on practical applications. These are exhibited by Tables 3 and 4.

$$
\begin{aligned}
C_{f_{x}=} & \operatorname{Re}_{x}^{-0.5}(1-\beta \theta)(1-\Phi)^{-5 / 2} \\
& \left(f^{\prime \prime}(0)+0.5(m-1) W b\left(f^{\prime \prime}(0)\right)^{3}\right), \\
C_{g_{y}=} & \operatorname{Re}_{y}^{-0.5} \Lambda^{0.5}(1-\beta \theta)(1-\Phi)^{-5 / 2} \\
& \left(g^{\prime \prime}(0)+0.5(m-1) W b\left(g^{\prime \prime}(0)\right)^{3}\right),
\end{aligned}
$$

$$
N u_{x}=-\operatorname{Re}_{x}^{0.5}\left[E_{2}+R d\left(1+\left(\theta_{r}-1\right) \theta(0)\right)^{3}\right] \theta^{\prime}(0),
$$

The local Reynolds numbers $\left(\operatorname{Re}_{x}, \operatorname{Re}_{y}\right)$ respectively in -axis directions are given by $\sqrt{\operatorname{Re}_{x}}=\left(d_{1} / v_{B f}\right)^{0.5} x$ and $\sqrt{\operatorname{Re}_{y}}=\left(d_{2} / v_{B f}\right)^{0.5} y$.

\section{Analysis of Results}

The solution was procured for the equations (9)-(11) using their corresponding constraints. For this, shooting and R.K. numerical procedures are executed. The solution makes us known that the velocity $\left(f^{\prime}(\xi), g^{\prime}(\xi)\right)$ and temperature $\theta(\xi)$ of the flow are well affected by many physical parameters such as Weissenberg number $(W b)$, Eckert number $(E k)$, Magnetic field parameter $(M f)$, nanoparticle volume fraction $(\Phi)$, ratio of temperatures $\left(\theta_{r}\right)$, parameter of stretching ratio $(\Lambda)$, power law index $(m)$ and irregular heat absorptive/generative coefficients $\left(H_{1}, H_{2}\right)$. The impression of all these parameters on $f^{\prime}(\xi), g^{\prime}(\xi)$ and $\theta(\xi)$ have been scrutinized by giving physical reasons with the abet of Figs. 2-24, which are drawn using MATLAB software. The thermal properties of $\mathrm{Cu}, \mathrm{Al}-\mathrm{Cu}$ alloy nanoparticles and methanol are reported in Table 1. In Table 2, we compared present outcomes with the results of Reddy et al. [37] for the validation. For acquiring the graphs we took $\beta=0.3, \Phi=0.1, \Lambda=0.3, M f=0.8, \theta_{r}=1.2, m=2$, $W b=0.3, H_{1}=0.4, H_{2}=0.3, E k=0.8$ and $\mathrm{Pr}=7.38$ (methonal). We repeated the same set of values to plot the graphs.

Figs. 2-4 are constructed to know the variation in the curves of $f^{\prime}(\xi), g^{\prime}(\xi)$ and $\theta(\xi)$ for rising values of viscosity parameter $\beta$. Physically a growth in the fluid viscosity generates a resistance in the flow. This resistance in the flow produces heat. Hence, we detect a decay in the velocity in $x, y$-directions as well as a hike in fluid temperature 
Table 1: Thermal properties for regular fluid and solidparticles

\begin{tabular}{ccccc}
\hline Thermal properties & $\rho\left(\mathrm{Kg} / \mathrm{m}^{3}\right)$ & $C_{p}(\mathrm{~J} / \mathrm{Kg} \mathrm{K})$ & $k(\mathrm{~W} / \mathrm{m} \mathrm{K})$ & $\sigma(\mathrm{S} / \mathrm{m})$ \\
\hline Methanol & 792 & 2546 & 0.2033 & $0.5 \times 10^{-6}$ \\
$\mathrm{Cu}$ & 8929 & 386 & 400 & $5.98 \times 10^{7}$ \\
Al-Cu alloy & 4133 & 747.89 & 112 & $1.49 \times 10^{7}$
\end{tabular}

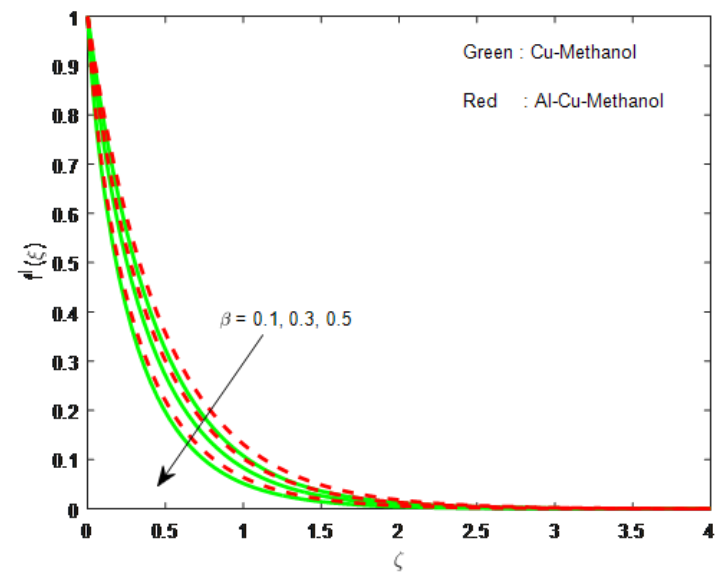

Fig. 2: Impression of $\beta$ on $f^{\prime}(\xi)$

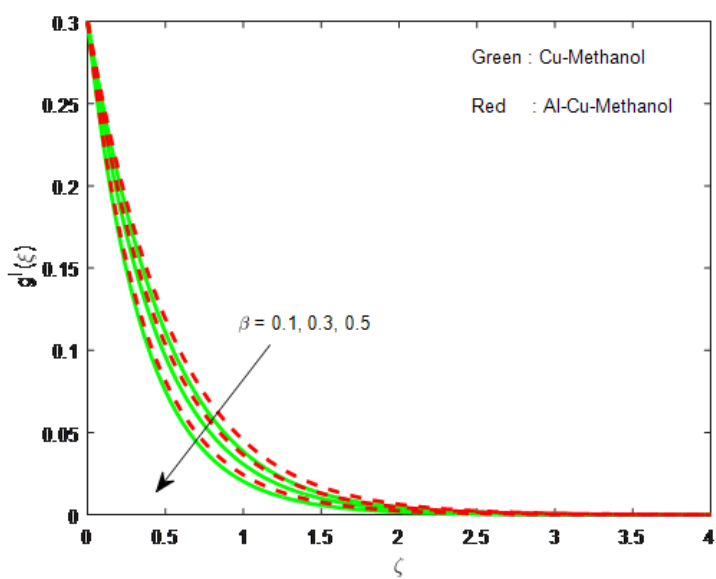

Fig. 3: Impression of $\beta$ on $g^{\prime}(\xi)$

with increase in $\beta$. The profiles of $\theta(\xi)$ for disparate values of $E k$ are plotted in Fig. 5. As fluid stores heat energy from frictional heat caused by $E k$, we watch an inflation in fluid temperature for rising values of $E k$. A keen observation of Fig. 5 enables us to state that initially there is no difference between the profiles of $\mathrm{Cu}$-methanol and $\mathrm{Al}-\mathrm{Cu}$ methanol but temperature curves of Al-Cu nanofluid beats that of other as $\zeta \rightarrow \infty$.

Fig. 6 elucidates the variation in $\theta(\xi)$ with $H_{1}=0.2$, 1.2 and 2.5. As we already mentioned $H_{2}=0.3$, therefore $H_{1}, H_{2}>0$. We know that positive values of $H_{1}, H_{2}$ gives rise to heat in the flow. Ergo, we notice a development in temperature distribution. Fig. 7 is the graphical represen-

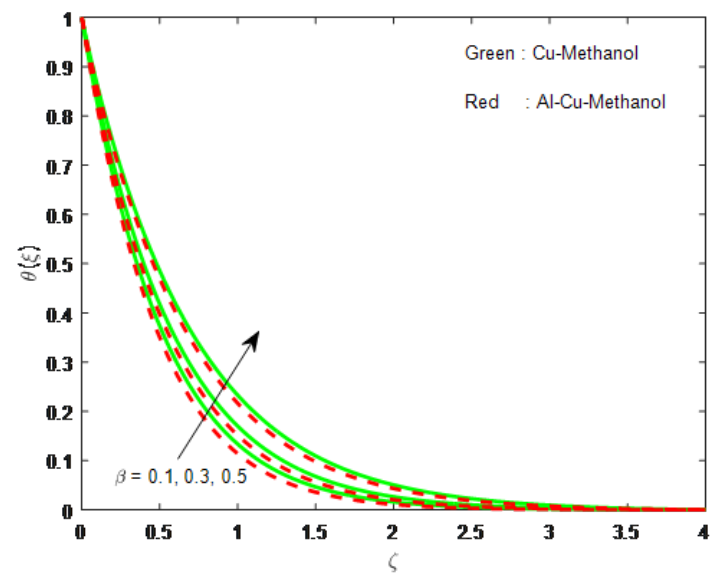

Fig. 4: Impression of $\beta$ on $\theta(\xi)$

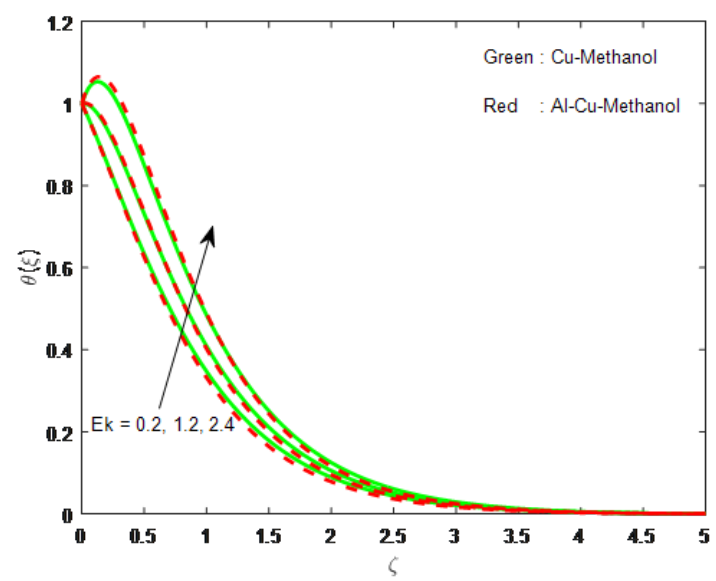

Fig. 5: Impression of $E k$ on $\theta(\xi)$

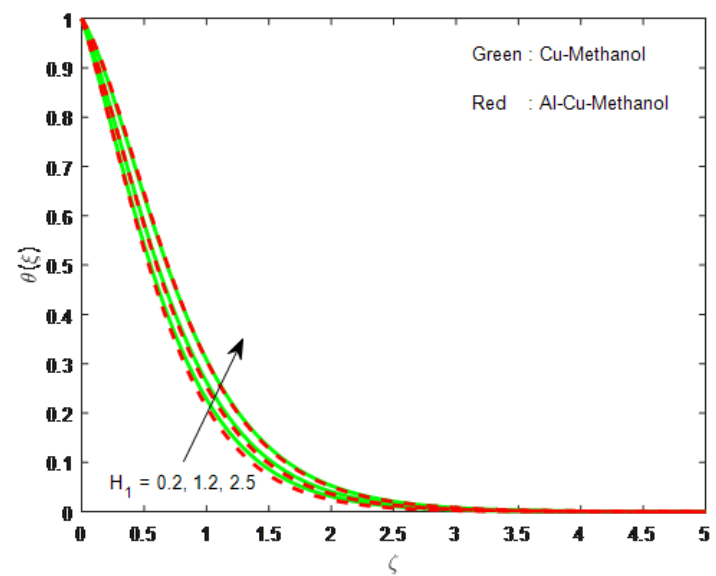

Fig. 6: Impression of $H_{1}$ on $\theta(\xi)$

tation of $\theta(\xi)$ vs negative values of $H_{2}$. For this graph, we taken $H_{1}=-0.4, H_{2}=-0.2,-1.4,-2.6$. It is expected out- 
Table 2: Validation of $-\theta^{\prime}(0)$ with Reddy et al. [37] by taking $E k=0, m=1, H_{1}=H_{2}=0$.

\begin{tabular}{ccccccc}
\hline Study & $\beta=0.3$ & $\beta=0.5$ & $\beta=0.7$ & $=1.1$ & $\theta_{r}=1.5$ & $=1.9$ \\
\hline Present $\left(-\theta^{\prime}(0)\right)$ & 0.7984 & 0.7820 & 0.7507 & 1.3465 & 1.0020 & 0.7557 \\
Ref: [37] $\left(-\theta^{\prime}(0)\right)$ & 0.7986 & 0.7821 & 0.7507 & 1.3463 & 1.0018 & 0.7555 \\
\hline
\end{tabular}

Table 3: Numerical values for $-\left(\frac{d \theta}{d \xi}\right),\left(\frac{d^{2} f}{d \xi^{2}}\right),\left(\frac{d^{2} g}{d \xi^{2}}\right)$ at reckoned utilizing Eqs. (13)-(15), for Cu-methanol liquid flow

\begin{tabular}{|c|c|c|c|c|c|c|c|c|c|c|c|}
\hline$\beta$ & $E k$ & $H_{1}$ & $\mathrm{H}_{2}$ & $W b$ & $m$ & $\Phi$ & $\Lambda$ & $\theta_{r}$ & $\begin{array}{l}-\left(\frac{d \theta}{d \xi}\right) \text { at } \\
\xi=0\end{array}$ & at $\xi=0$ & at $\xi=0$ \\
\hline 0.1 & & & & & & & & & 0.6670 & -1.7886 & -0.3949 \\
\hline 0.3 & & & & & & & & & 0.6359 & -2.1119 & -0.4688 \\
\hline \multirow[t]{25}{*}{0.5} & & & & & & & & & 0.5745 & -2.7131 & -0.5913 \\
\hline & 0.2 & & & & & & & & 0.6409 & -2.5667 & -0.6282 \\
\hline & 1.2 & & & & & & & & -0.0610 & -2.4256 & -0.6066 \\
\hline & 2.4 & & & & & & & & -0.9300 & -2.2710 & -0.5811 \\
\hline & & 0.2 & & & & & & & 0.8212 & -2.1796 & -0.4817 \\
\hline & & 1.2 & & & & & & & 0.6411 & -2.1388 & -0.4750 \\
\hline & & 2.5 & & & & & & & 0.4061 & -2.0876 & -0.4664 \\
\hline & & & -0.2 & & & & & & 0.8478 & -2.1649 & -0.4780 \\
\hline & & & -1.4 & & & & & & 1.0523 & -2.2183 & -0.4870 \\
\hline & & & -2.6 & & & & & & 1.2225 & -2.2615 & -0.4939 \\
\hline & & & & 0.1 & & & & & 0.2202 & -2.3415 & -0.5883 \\
\hline & & & & 0.4 & & & & & 0.2228 & -2.7835 & -0.6662 \\
\hline & & & & 0.7 & & & & & 0.2181 & -3.3401 & -0.7369 \\
\hline & & & & & 1 & & & & 0.6310 & -1.8638 & -0.4268 \\
\hline & & & & & 2 & & & & 0.5464 & -2.5704 & -0.5290 \\
\hline & & & & & 3 & & & & 0.4484 & -3.7373 & -0.6108 \\
\hline & & & & & & 0.05 & & & 0.1990 & -2.3779 & -0.5951 \\
\hline & & & & & & 0.10 & & & 0.2222 & -2.4806 & -0.6152 \\
\hline & & & & & & 0.15 & & & 0.2390 & -2.5456 & -0.6290 \\
\hline & & & & & & & 0.1 & & 0.1570 & -2.4380 & -0.1974 \\
\hline & & & & & & & 0.5 & & 0.3398 & -2.5624 & -1.0999 \\
\hline & & & & & & & 0.9 & & 0.6647 & -2.8243 & -2.4477 \\
\hline & & & & & & & & 1.1 & 0.2222 & -2.4806 & -0.6152 \\
\hline & & & & & & & & 1.3 & 0.1885 & -2.4450 & -0.6078 \\
\hline & & & & & & & & 1.5 & 0.1563 & -2.4126 & -0.6006 \\
\hline
\end{tabular}

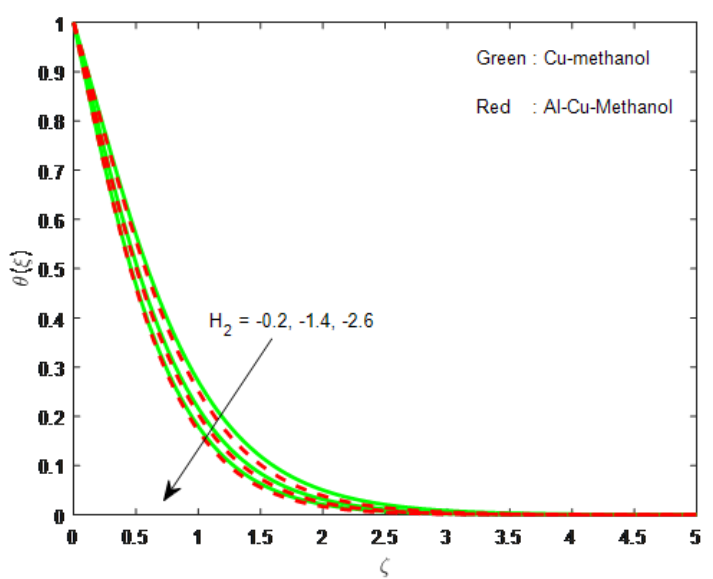

Fig. 7: Impression of $\mathrm{H}_{2}$ on $\theta(\xi)$

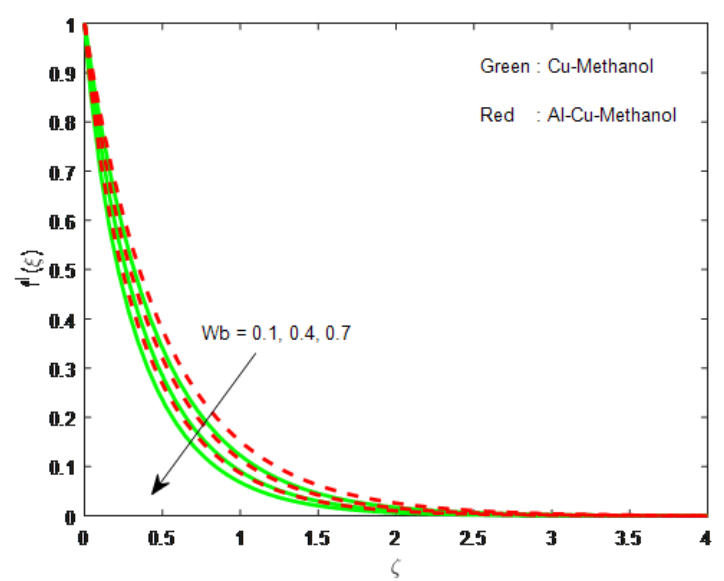

Fig. 8: Impression of $w b$ on $f^{\prime}(\xi)$ 
Table 4: Numerical values for $-\left(\frac{d \theta}{d \xi}\right),\left(\frac{d^{2} f}{d \xi^{2}}\right),\left(\frac{d^{2} g}{d \xi^{2}}\right)$ at $\xi=0$ reckoned utilizing Eqs. (13)-(15), for Al-Cu-methanol liquid flow

\begin{tabular}{|c|c|c|c|c|c|c|c|c|c|c|c|}
\hline$\beta$ & $E k$ & & $\mathrm{H}_{2}$ & & $m$ & $\Phi$ & $\Lambda$ & $\theta_{r}$ & $\begin{array}{l}-\left(\frac{d \theta}{d \xi}\right) \text { at } \\
\xi=0\end{array}$ & at $\xi=0$ & $\begin{array}{l}\left(\frac{d^{2} g}{d \xi^{2}}\right) \text { at } \\
\xi=0\end{array}$ \\
\hline 0.1 & & & & & & & & & 0.6767 & -1.5665 & -0.3576 \\
\hline 0.3 & & & & & & & & & 0.6514 & -1.8660 & -0.4290 \\
\hline \multirow[t]{25}{*}{0.5} & & & & & & & & & 0.5974 & -2.4274 & -0.5494 \\
\hline & 0.2 & & & & & & & & 0.6543 & -2.3705 & -0.6011 \\
\hline & 1.2 & & & & & & & & -0.0982 & -2.2311 & -0.5778 \\
\hline & 2.4 & & & & & & & & -1.0311 & -2.0788 & -0.5506 \\
\hline & & 0.2 & & & & & & & 0.8340 & -1.9258 & -0.4410 \\
\hline & & 1.2 & & & & & & & 0.6362 & -1.8858 & -0.4338 \\
\hline & & 2.5 & & & & & & & 0.3782 & -1.8359 & -0.4248 \\
\hline & & & -0.2 & & & & & & 0.8674 & -1.9133 & -0.4378 \\
\hline & & & -1.4 & & & & & & 1.0628 & -1.9566 & -0.4455 \\
\hline & & & -2.6 & & & & & & 1.2285 & -1.9921 & -0.4516 \\
\hline & & & & 0.1 & & & & & 0.2007 & -2.1585 & -0.5612 \\
\hline & & & & 0.4 & & & & & 0.2108 & -2.5608 & -0.6363 \\
\hline & & & & 0.7 & & & & & 0.2118 & -3.0634 & -0.7048 \\
\hline & & & & & 1 & & & & 0.6427 & -1.6495 & -0.3899 \\
\hline & & & & & 2 & & & & 0.5772 & -2.2729 & -0.4869 \\
\hline & & & & & 3 & & & & 0.4919 & -3.3210 & -0.5664 \\
\hline & & & & & & 0.05 & & & 0.1875 & -2.2630 & -0.5788 \\
\hline & & & & & & 0.10 & & & 0.2055 & -2.2854 & -0.5871 \\
\hline & & & & & & 0.15 & & & 0.2198 & -2.2939 & -0.5922 \\
\hline & & & & & & & 0.1 & & 0.1397 & -2.2489 & -0.1896 \\
\hline & & & & & & & 0.5 & & 0.3250 & -2.3554 & -1.0378 \\
\hline & & & & & & & 0.9 & & 0.6594 & -2.5778 & -2.2457 \\
\hline & & & & & & & & 1.1 & 0.2055 & -2.2854 & -0.5871 \\
\hline & & & & & & & & 1.3 & 0.1782 & -2.2529 & -0.5800 \\
\hline & & & & & & & & 1.5 & 0.1508 & -2.2228 & -0.5732 \\
\hline
\end{tabular}

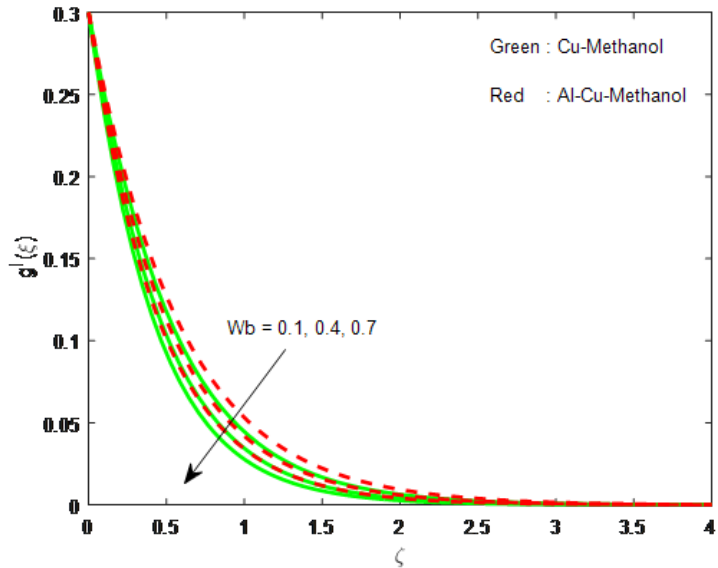

Fig. 9: Impression of $w b$ on $g^{\prime}(\xi)$

come that temperature decays with $H_{1}, H_{2}<0$. The behavior of dimensionless velocity and temperature with distinct values of Weissenberg number $(W b)$ is bestowed in Figs. 8-10. An improvement in the values of gives thickness to the fluid and hence deterioration in fluid motion occurs. As a consequence, greater values of $W b$ shrinks the veloc-

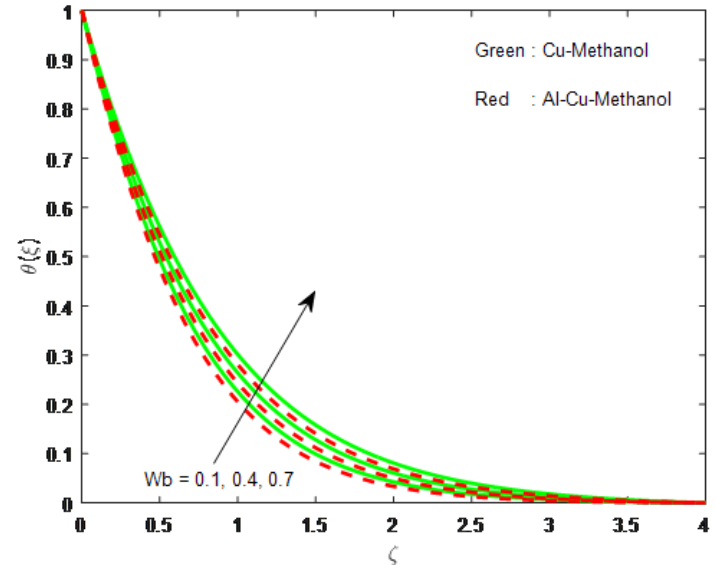

Fig. 10: Impression of $w b$ on $\theta(\xi)$

ity field. Since thicker liquid supplies heat energy, we discover an upsurge in $\theta(\xi)$ fro Fig. 10.

The nature of the curves $f^{\prime}(\xi), g^{\prime}(\xi)$ and $\theta(\xi)$ under the action of stretching ratio parameter $\Lambda$ is portrayed in Figs. 11-13. Velocity in $y$-direction grows with $\Lambda$ but shrinks in $x$-direction. Also, it is fascinating to comment 


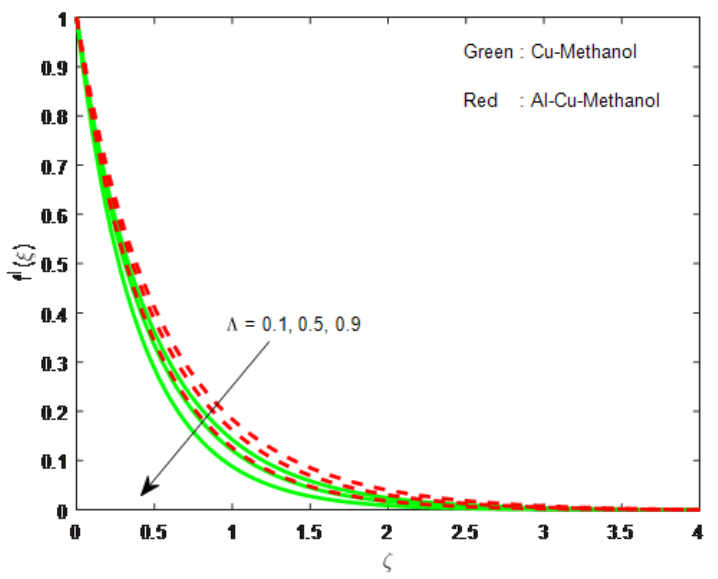

Fig. 11: Impression of $\Lambda$ on $f^{\prime}(\xi)$

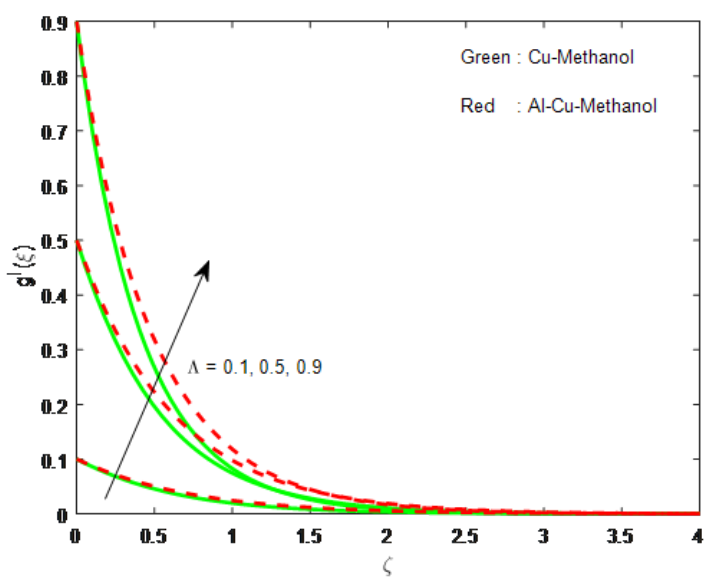

Fig. 12: Impression of $\Lambda$ on $g^{\prime}(\xi)$

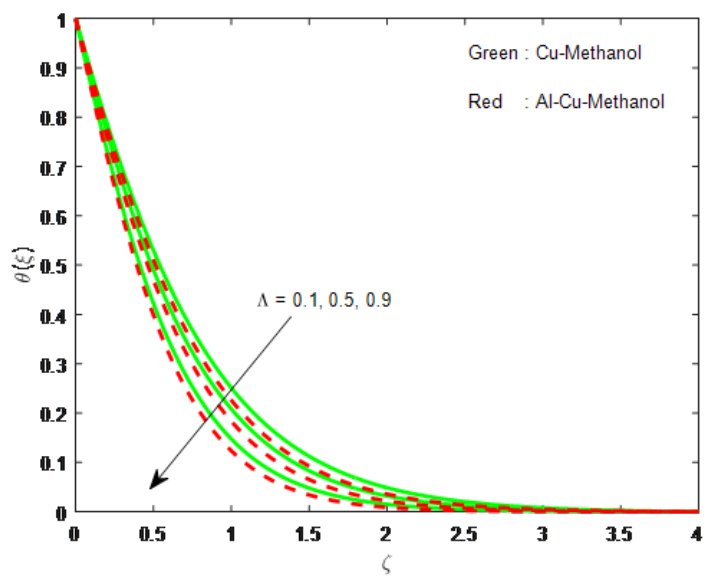

Fig. 13: Impression of $\Lambda$ on $\theta(\xi)$

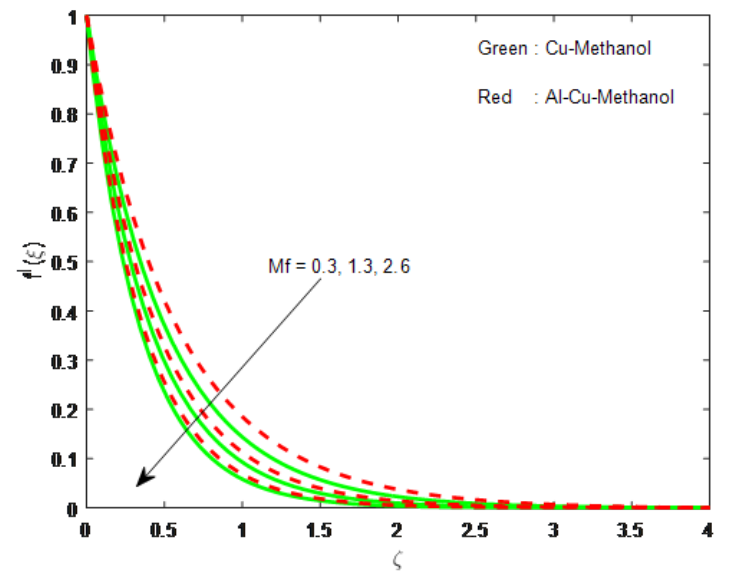

Fig. 14: Impression of Mf on $f^{\prime}(\xi)$

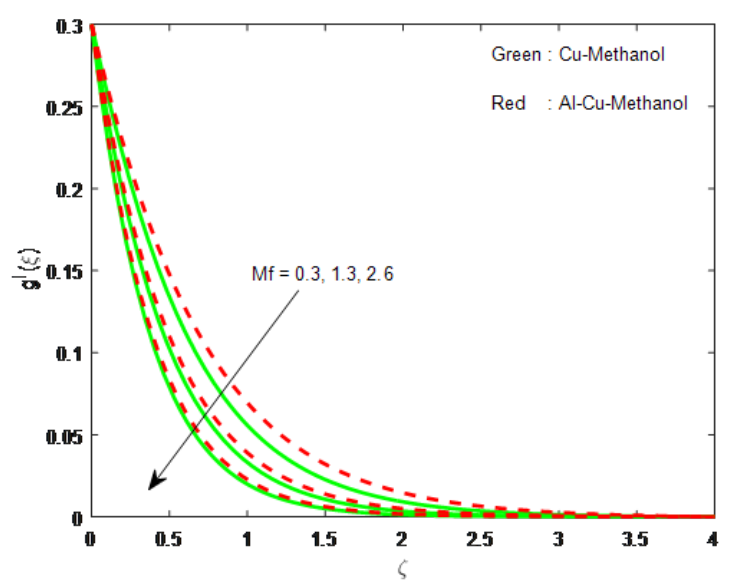

Fig. 15: Impression of Mf on $g^{\prime}(\xi)$

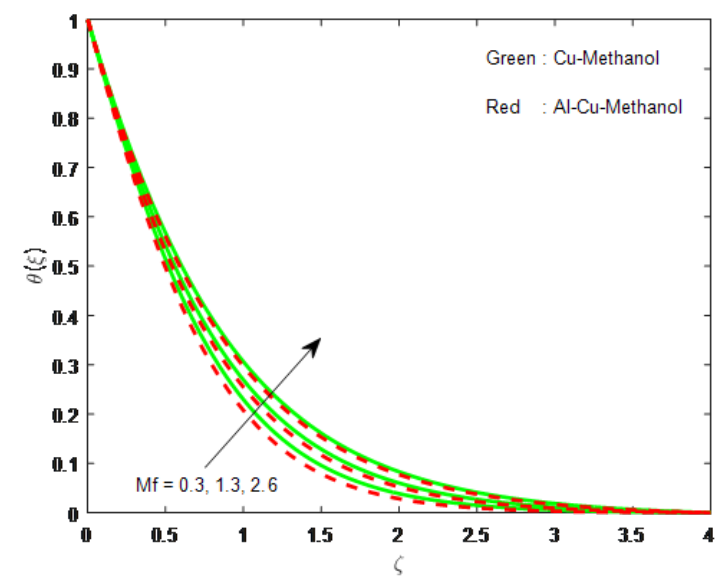

Fig. 16: Impression of Mf on $\theta(\xi)$ 


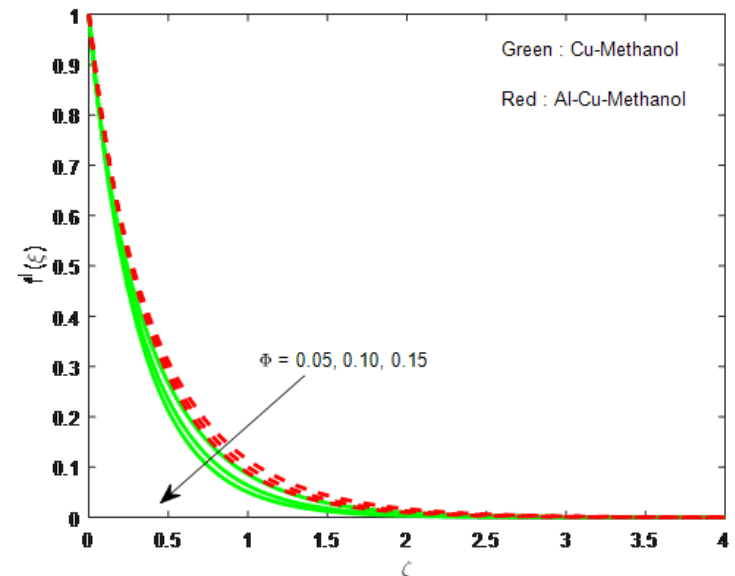

Fig. 17: Impression of $\Phi$ on $f^{\prime}(\xi)$

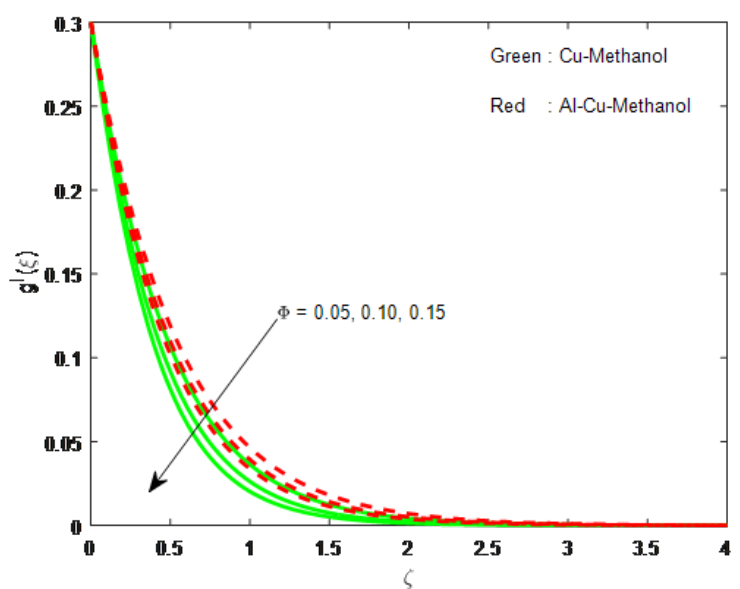

Fig. 18: Impression of $\Phi$ on $g^{\prime}(\xi)$

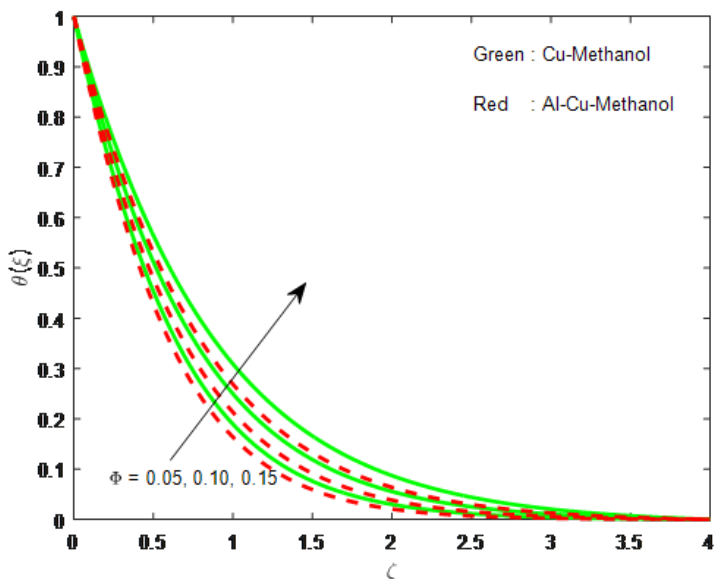

Fig. 19: Impression of $\Phi$ on $\theta(\xi)$

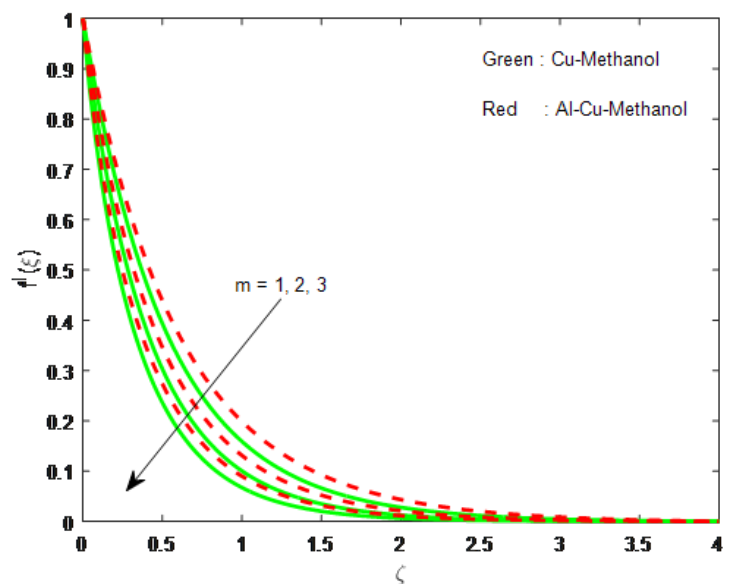

Fig. 20: Impression of $m$ on $f^{\prime}(\xi)$

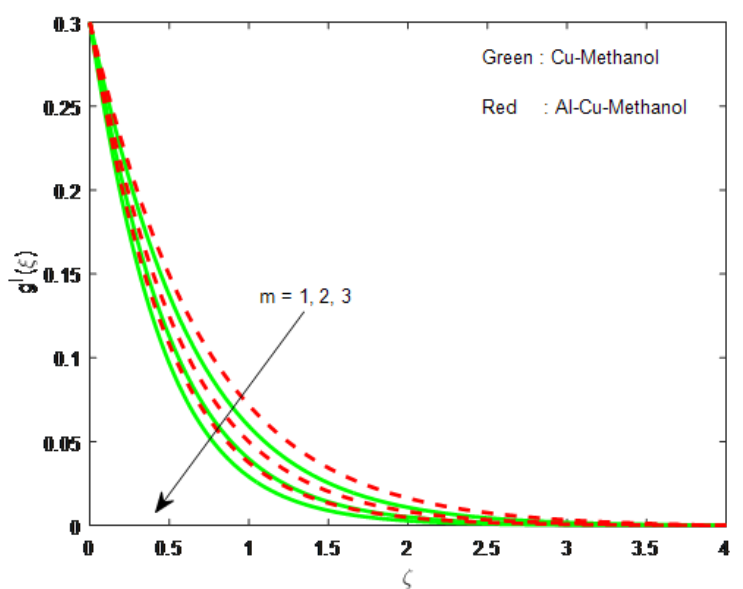

Fig. 21: Impression of $m$ on $g^{\prime}(\xi)$

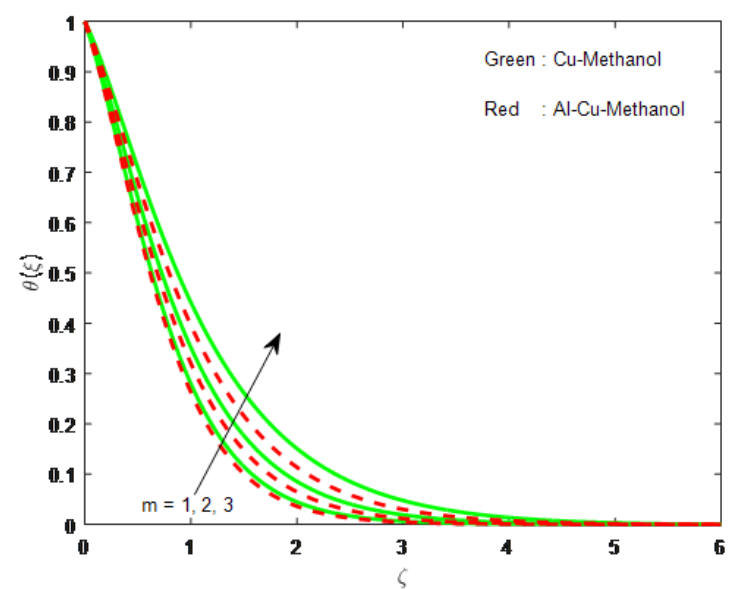

Fig. 22: Impression of $m$ on $\theta(\xi)$ 


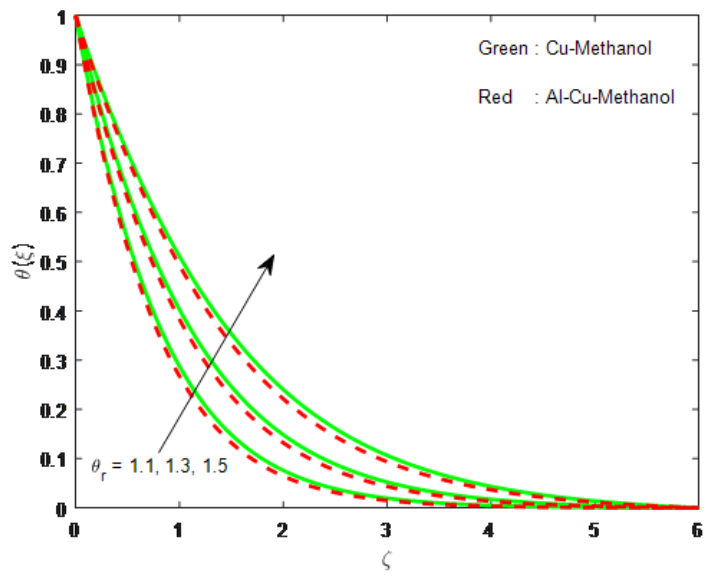

Fig. 23: Impression of $\theta_{r}$ on $\theta(\xi)$

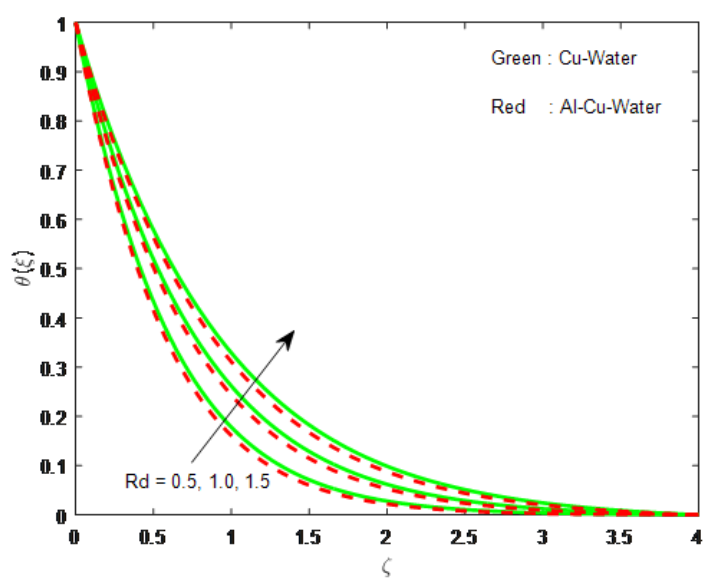

Fig. 24: Impression of $R d$ on $\theta(\xi)$

that secondary velocity $\left(g^{\prime}(\xi)\right)$ is well affected by $\Lambda$. But a dissimilar response is heeded in primary velocity. Fig. 13 clinches that temperature field decays with $\Lambda$. Figs. 14 16 describe how velocity and temperature are affected by Lorentz force. These Figs. disclose that a wax in magnetic field () wanes the velocity in both $x, y$ - axis directions (See Figs. 14, 15). But a gain in fluid temperature is identified from Fig. 16. There is a well known fact that magnetic field yields Lorentz force, which is proficient to decelerate the flow speed and supplies heat energy to the flow.

Figs. 17-19 are sketched to explore the impact of (percentage of solid nano particles in the base liquid) on $f^{\prime}(\xi), g^{\prime}(\xi)$ and $\theta(\xi)$. As we anticipated, an upswing in $\Phi$ ebbs the flow speed in both -directions (see Figs. 17 and 18). This may happen owing to the colloidal suspension of nanoparticles in carrier liquid. If we increase the percentage of nanoparticles in methanol heat will move from methanol to particles. This phenomenon helps the nanofluid to acquire higher temperature, which is clear from Fig. 19. Also, from Table 1 it is understandable that thermal conductivity of Al-Cu alloy is (112 W/mK) is lesser than that of $\mathrm{Cu}$ particles $(400 \mathrm{~W} / \mathrm{mK})$. Therefore an upsurge in $\Phi$ adds excess temperature to $\mathrm{Cu}$-methanol when compared with Al-Cu-methanol.

Figs. 20-22 clarify how velocity and temperature fields are efected by power law index $m$. We glimpse that increase in $m$ worsens the flow velocity in both the directions under consideration. Meanwhile a growth in $\theta(\xi)$ is discerned. The features of temperature ratio $\left(\theta_{r}\right)$, and radiation $(R d)$ on the flow field are described via Figs. 23 and 24 . It is perceptible that the profiles of risen with a strength in either of these parameters. Physically, sheet temperature improves for climbing values of $\theta_{r}$. Fig. 24 concurs with the fact that radiation parameter (as $R d \rightarrow \infty$ ) has inclination to ameliorate the flow heat i.e. increases the thermal boundary layer thickness.

From all the Figs. 2-24, one may easily conclude that Velocity of Al-Cu-methanol is comparatively better than that of Cu-Methanol. Also the magnitude of fluid temperature is found to be high in Cu-methanol flow when compared to Al-Cu-methanol flow.

Tables 3and 4 let us to say that Al-Cu alloy nanoparticles in the carrier liquid leads to superior heat transfer ability instead of using only Aluminum nanoparticles. Also, lower values of $E k$ extremely augments the rate of heat transport. Heat absorptive flow superiorly growths the Nusselt number when compared to heat generative flow. As usually, rising values of $E k$ heightens the friction factors in dual directions of flow. We observe a decay in the values of $f^{\prime \prime}(0), g^{\prime \prime}(0)$ and $-\theta^{\prime}(0)$ for increasing values of viscosity parameter and power law index. It is salient to grasp that increase in suppresses the wall friction along $y$-direction even though the same parameter boosts the velocity. The impact of Weissenberg number and nanoparticles volume fraction is similar on wall friction and heat transfer rate, i.e. both parameters enlarges $-\theta^{\prime}(0)$ but decays wall frictions $\left(f^{\prime \prime}(0), g^{\prime \prime}(0)\right)$.

\section{Concluding Remarks}

The Joule heating and variable heat source/sink impacts are reckoned while setting the equation of energy. Problem's solution is procured by the application of Shooting and R.K. numerical procedures. Our perusal leads to the following significant conclusions. 
- $\quad$ Mixing Al-Cu alloy nanoparticles in the carrier liquid leads to superior heat transfer ability instead of mixing only Aluminum nanoparticles.

- Higher values of Weissenberg number or viscosity parameter have inclination to exalt the thermal field.

- $\quad$ The viscosity and power law index parameters exhibit similar behavior in lessening the Nusselt number.

- Using of Al-Cu alloy particles instead of Cu particles makes the fluid to move quickly along the surface.

- $\quad$ Space dependent varying heat sink/source (due to $H_{1}, H_{2}$ ) respectively improves/worsens the rate of heat transfer.

- All parameters apart from stretching rate ameliorate the secondary velocity $\left(g^{\prime}(\xi)\right)$.

- An enhancement in either the stretching rate parameter or nanoparticle volume fraction strengthens the Nusselt number.

\section{References}

[1] S.U.S. Choi, Enhancing thermal conductivity of fluids with nanoparticles, Proc. ASME Int. Mech. Eng. Cong. Exp. 66 (1995) 99-105.

[2] J.A. Eastman, S.U.S. Choi, S. Li, W. Yu, L.J. Thompson, Anomalously increased effective thermal conductivities of ethyleneglycol based nanofluids containing copper nanoparticles, Appl. Phys. Lett. 78 (2001) 718-720.

[3] J. Buongiomo, Convective transport in nanofluids, J. Heat Transf. 128 (2006) 240-250.

[4] F. Mabood, W.A. Khan, M.M. Yovanovich, Forced convection of nanofluid flow across horizontal circular cylinder with convective boundary condition, J. Mol. Liq. 222 (2016) 172-180.

[5] J.V.R. Reddy, V. Sugunamma, N. Sandeep, Thermophoresis and Brownian motion effects on unsteady MHD nanofluid flow over a slendering stretching surface with slip effects, Alexandria Eng. J. (2017) http://dx.doi.org/10.1016/j.aej.2017.02.014.

[6] F. Noor, A. Voroahtsov, M. Lerner, E.P.F. Bandarra, D. Wen, Thermal chemical characteristics of Al-Cu alloy nanoparticles, The J. Physical Chem. C 119 (2015) 14001-14009.

[7] C.S.K. Raju, M.M. Hoque, N.N. Anika, S.U. Mamatha, P. Sharma, Natural convective heat transfer analysis of unsteady MHD Carreau nanofluid over a cone packed with alloy nanoparticles, Powder Tech. 317 (2017) 408-416.

[8] J. Boyd, J.M. Buick, S. Green, Analysis of the Casson and Carreau-Yasuda non-Newtonian blood models in steady and oscillatory flows using the lattice Boltzmann method, Phys. Fluids 19 (2007) 093103, doi: 10.1063/1.2772250.

[9] N.S. Akbar, S. Nadeem, R.U. Haq, S. Ye, MHD stagnation point flow of Carreau fluid toward a permeable shrinking sheet: Dual solutions, Ain Shams Eng. J. 5 (2014) 1233-1239.

[10] M.Y. Malik, S. Bilal, T. Salahuddin, K.U. Rehman, Three dimensional Williamson fluid flow over a linear stretching surface,
Math. Sci. Lett., Int. J. 6 (2017) 53-61.

[11] M. Khan, M. Azam, Unsteady heat and mass transfer mechanism in MHD Carreau nanofluid flow, J. Mol. Liq. 225 (2017) 554-562.

[12] T. Hayat, M. Waqas, A. Alsaedi, G. Bashir, F. Alzahrani, Magnetohydrodynamic (MHD) stretched flow of tangent hyperbolic nanoliquid with variable thickness, J. Mol. Liq. 229 (2017) 178184.

[13] M. Khan, M. Irfan, W. A. Khan, Thermophysical properties of unsteady 3D flow of magneto Carreau fluid in the presence of chemical species: a numerical approach, J. Braz. Soc. Mech. Sci. Eng. 40 (2018) https://doi.org/10.1007/s40430-0180964-4.

[14] K.S. Adegbie, F.I. Alao, Flow of temperature-dependent viscous fluid between parallel heated walls: Exact analytical solutions in the presence of viscous dissipation , J. Math. Stat. 3 (2007) 12-14.

[15] H.A. Attia, Unsteady hydromagnetic Couetteflow of dusty fluid temperature dependent viscosity and thermal conductivity under exponential decaying pressure gradient, Comm. Nonlinear Sci. Num. Simul. 13 (2008) 1077-1088.

[16] D. Pal, H. Mondal, Influence of temperature-dependent viscosity and thermal radiation on MHD forced convection over a non-isothermal wedge, Appl. Math. Comp. 212 (2009) 194 208.

[17] D. Pal, H. Mondal, Effects of temperature dependent viscosity and variable thermal conductivity on MHD non-Darcy mixed convective diffusion of species over a stretching sheet, J. Egypt. Math. Soc. 22 (2014) 123-133.

[18] A.M. Salem, The effects of variable viscosity, viscous dissipation and chemical reaction on heat and mass transfer flow of MHD micropolar fluid along a permeable stretching sheet in a non-Darcian porous medium, Math. Prob. Eng. 2013 (2013) Article Id: 185074.

[19] S. Nadeem, R.U. haq, N.S. Akbar, Z.H. Khan, MHD threedimensional Casson fluid flow past a porous linearly stretching sheet, Alexandria Eng. J. 52 (2013) 577-582.

[20] J.A. Khan, M. Mustafa, T. hayat, A. Alsaedi, On threedimensional flow and heat transfer over a non-linearly stretching sheet: Analytical and numerical solutions, Plos One 9 (2014) e107287.

[21] M.M. Rashidi, A.A. Hakeem, N.V. Ganesh, B. Ganga, M. Sheikholeslami, E. Momoniat, Analytical and numerical studies on heat transfer of a nanofluid over a stretching/shrinking sheet with second-order slip flow model, Int. J. Mech. Mater. Eng. 11 (2016) doi: 10.1186/s40712-016-0054-2.

[22] M. Ramzan, M. Farooq, T. Hayat, J.D. Chung, Radiative and Joule heating effects in the MHD flow of a micropolar fluid with partial slip and convective boundary condition, J. Mol. Liq. 221 (2016) 394-400.

[23] J.V.R. Reddy, V. Sugunamma, N. Sandeep, Effect of frictional heating on radiative ferrofluid flow over a slendering stretching sheet with aligned magnetic field, Europ. Phys. J. Plus 132 (2017) doi: 10.1140/epjp/i2017-11287-1.

[24] K.A. Kumar, J.V.R. Reddy, V. Sugunamma, N. Sandeep, Magnetohydrodynamic Cattaneo-Christov flow past a cone and a wedge with variable heat source/sink, Alexandria Eng. J. (2017) http://dx.doi.org/10.1016/j.aej.2016.11.013.

[25] J.V.R. Reddy, K.A. Kumar, V. Sugunamma, N. Sandeep, Effect of cross diffusion on MHD non-Newtonian fluids flow past a 
stretching sheet with non-uniform heat source/sink: A comparative study, Alexandria Eng. J. (2017) http://dx.doi.org/10. 1016/j.aej.2017.03.008.

[26] B. J. Gireesha, B. Mahanthesh, K. L. Krupalakshmi, Hall effect on two-phase radiative flow of magneto-dusty-nnaoliquid with irregular heat generation/consumption, Res. Phys. 7 (2017) 4340-4348.

[27] T. Hayat, S. Qayyum, A. Alsaedi, S. Asghar, Radiation effects on the mixed convection flow induced by an inclined stretching cylinder with non-uniform heat source/sink, Plos One 12 (2017) e0175584.

[28] R.A. Shah, T. Abbas, M. Idress, M. Ullah, MHD Carreau fluid slip flow over a porous stretching sheet with viscous dissipation and variable thermal conductivity, Bound. Value. Prob. 94 (2014) doi: 10.1186/s13661-017-0827-4.

[29] M.J. Babu, N. Sandeep, M.E. Ali, O.A. Nuhait, Magnetohydrodynamic dissipative flow across the slendering stretching sheet with temperature dependent variable viscosity, Res. Phys. 7 (2017) 1801-1807.

[30] T. Muhammad, T. Hayat, A. Alsaedi, A. Qayyum, Hydromagnetic unsteady squeezing flow of Jeffrey fluid between two parallel plates, Chin. J. Phys. (2017) http://dx.doi.org/10.1016/j.cjph. 2017.05.008.

[31] S.A. Shehzad, T. Hayat, A. Alsaedi, M.A. Obid, Nonlinear thermal radiation in three dimensional flow of Jeffrey nanofluid: A model for solar energy, Appl. Math. Comp. 248 (2014) 273286.

[32] C.S.K. Raju, N. Sandeep, Unsteady three-dimensional flow of Casson-Carreau fluids past a stretching surface, Alexandria Eng. J. 55 (2016) 1115-1126.

[33] S.A. Shehzad, Z. Abdullah, A. Alsaedi, F.M. Abbasi, T. Hayat, Thermally radiative three-dimensional flow of Jeffrey nanofluid with internal heat generation and magnetic field, J. Magn. Magn. Mater. 397 (2016) 108-114.
[34] S. Bilal, M.Y. Malik, A. Hussain, M. Khan, Effects of temperature dependent conductivity and absorptive/generative heat transfer on MHD three dimensional flow of Williamson fluid due to bidirectional nonlinear stretching surface, Res. Phys. 7 (2017) 204-212.

[35] J.V.R. Reddy, V Sugunamma, N. Sandeep, Impact of nonlinear radiation on 3D magnetohydrodynamic flow of methanol and kerosene based ferrofluids with temperature dependent viscosity, J. Mol. Liq. 236 (2017) 93-100.

[36] S. Hina, M. Munir, M. Mustafa, A non-Fourier heat flux approach to model MHD Oldroyd-B fluid flow due to bidirectional stretching surface, Int. J. Mech. Sci. 131 (2017) 146-154.

[37] B. C. Shekar, A. Ramesh, N. Kishan, Effects of variable viscosity and thermal conductivity on MHD boundary layer flow of nanofluid with thermal radiation, J. nanofluids 6 (2017) 59-70.

[38] K. Kaladhar, C. Ramreddy, D. Srinivasacharya, T. Pradeepa, Analytical study for Soret, Hall and Joule heating effects on natural convection flow saturated porous medium in a vertical channel, Math. Sci. 10 (2016) 139-148.

[39] N. Praveen, M.A. Alim, Joule heating effect on magnetohydrodynamic natural convection flow along a vertical wavy surface, J. naval. Arch. Marine. Eng. 9 (2012) 11-24.

[40] T. Hayat, A. Shafiq, A. Alsaedi, Effect of Joule heating and thermal radiation in flow of third grade fluid over radiative surface, Plos One (2014) 9 e83153.

[41] D.H. Babu, P.S. Narayana, Joule heating effects on MHD mixed convection flow of a Jeffrey fluid over a stretching sheet with power law heat flux: A numerical study, J. Magn. Magn. Mater. 412 (2016) 185-193.

[42] A.S. Dogonchi, D.D. Ganji, Analytical solution and heat transfer of two-phase nanofluid flow between non-parallel walls considering Joule heating effect, Powder Tech. 318 (2017) 390400. 